\title{
Systematic review and meta-analysis of randomized controlled trials on Wenxin keli
}

This article was published in the following Dove Press journal:

Drug Design, Development and Therapy

14 November 2016

Number of times this article has been viewed

\section{Xiaoyi Wang \\ Ying Wang \\ Xiaoyuan Feng \\ Ying Lu \\ Yu Zhang \\ Wenwen Wang \\ Wentao Zhu}

School of Management, Beijing University of Chinese Medicine, Beijing, People's Republic of China
Correspondence: Wentao Zhu School of Management, Beijing University of Chinese Medicine, No II, Beijing North Third Ring Road, Chaoyang, Beijing, People's Republic of China Tel +861064286475

Fax +86 1064286475

Email zhuwt@bucm.edu.cn
Objective: The aim of the study was to evaluate the effectiveness, safety, and cost associated with Wenxin keli in the treatment of cardiovascular diseases based on meta-analysis.

Methods: The terms "Wenxin keli" and "Wenxin" were used as the search terms in the PubMed, ProQuest, Springer, the Cochrane Library, CNKI (China National Knowledge Infrastructure), VIP (Chinese Scientific Journals Database), and Wan fang electronic databases (from January 2000 to October 2015). Relevant print journals and conference papers were also searched. Studies on randomized controlled trials (RCTs) of Wenxin keli used in the treatment of cardiovascular diseases were screened, and its indications were classified. Meta-analysis of these studies was conducted using the RevMan 5.2 software.

Results: A total of 49 RCTs $(n=4,610)$ were included, 29 of which focused on arrhythmia, seven on angina, seven on heart failure, two on viral myocarditis, and four on menopausal syndrome. Analysis of the therapeutic indications of Wenxin keli showed that it was comparatively more curative and effective than other available treatments for cardiovascular diseases.

Conclusion: Wenxin keli showed better clinical efficacy in the treatment of arrhythmia, angina, and heart failure; however, more high-quality evidence is needed to support its use in the clinical setting.

Keywords: Wenxin keli, cardiovascular disease, meta-analysis, systematic review

\section{Introduction}

The number of patients affected by cardiovascular disease is steadily increasing because of socioeconomic development and modern lifestyles. ${ }^{1}$ A report from the World Health Organization reveals that chronic noncommunicable diseases have now become the leading cause of death worldwide. In 2008, 36 million individuals died of chronic noncommunicable diseases ( $63 \%$ of total deaths), of which $48 \%$ died of cardiovascular diseases. ${ }^{2}$ In recent years, there has been a shift in the medical paradigm, and cardiovascular and cerebrovascular diseases have now become a serious threat to public health. ${ }^{3}$ According to a report on Cardiovascular Diseases in China (2013), presented at the China Heart Congress, about one-fifth of all Chinese adults are currently affected with cardiovascular and cerebrovascular diseases. ${ }^{4}$ Furthermore, during the past five years, mortality due to cardiovascular diseases ranks first among all causes of death. ${ }^{4}$ Social and economic development has led to dramatic changes in lifestyles, including an increase in energy intake, less manual labor, accelerated pace of life, competitive pressures, and exposure to other risk factors associated with cardiovascular and other chronic noncommunicable diseases, which are causes for concern. ${ }^{5}$

Wenxin keli consists of several kinds of Chinese herbs including Huang Jing, Codonopsis, amber, Panax, and nard. Wenxin keli has been used clinically in the treatment of qi and yin deficiency, systolic blood stasis due to restless heart palpitations, $\mathrm{Br}$
$\mathrm{Ne}$
hereby for commercial use of this work, please see paragraphs 4.2 and 5 of our Terms (hitps://www.dovepress.com/terms.php). 
shortness of breath, chest pain, premature ventricular contractions (PVC), and atrial premature beats. It is one of the main forms of treatment for cardiovascular disease in Chinese medicine. In recent years, many researchers have evaluated the use of Wenxin keli in the treatment of cardiovascular disease; however, further evaluation is necessary. Therefore, the present study aimed to conduct a comprehensive evaluation of the efficacy and safety of Wenxin keli, and provide the basis for its use as a medication for cardiovascular disease.

\section{Materials and methods}

\section{Literature search}

We performed systematic searches for randomized controlled trials (RCTs) designed to evaluate the clinical efficacy of Wenxin keli in CNKI (China National Knowledge Infrastructure), Wan fang, VIP (Chinese Scientific Journals Database), PubMed, the Cochrane Library, Springer, and ProQuest from January 1, 2000 to September 7, 2015 using "Wenxin keli" and "Wenxin" as the search terms.

\section{Inclusion and exclusion criteria}

Based on the Cochrane Collaboration Handbook standards, the following inclusion criteria were formulated for the selected literature: all published domestic and international RCTs on Wenxin keli; comparable baseline test data; interventions with individual drugs and Wenxin keli doses of $9 \mathrm{~g}$, three times/day; any particular course of treatment; publications in Chinese and English. Diagnostic criteria used in the present study were based on authoritative Chinese and other countries diagnostic criteria. The exclusion criteria were as follows: duplicate publications, reports of combination therapy effects on treatment, descriptive studies, studies involving animal testing, conflicting before and after data (such as, the sum of the data not matching the total), and reports without statistical indicators.

\section{Quality assessment}

Study quality was evaluated with an improved version of the Jadad questionnaire, considering mainly four aspects: 1) random sequence generation (2 points); 2) randomized hiding (2 points); 3) blinding (2 points); 4) a withdrawal period (1 point). Two reviewers independently completed the assessment, and the mean score of the two reviewers was used as the final quality score of the selected studies. In the assessment of RCTs, 1-3 points were considered as low quality, and 4-7 points indicated high quality.

A unified data extraction sheet was derived, based on blinding characteristics in previously published medical literature, for use by the two reviewers. The information thereby extracted was then cross-checked. The extracted data included:
1) document specifications: first author, publication year, and title;

2) subjects: disease, diagnostic criteria, inclusion and exclusion criteria, sample size, etc;

3) interventions: medication, dosage, route of administration, duration of treatment, etc;

4) results: efficacy indicators.

\section{Statistical analysis}

The RevMan 5.2 software, provided by the Cochrane Collaboration, was used to conduct the meta-analysis. Count data were used to determine the odds ratio (OR) and $95 \%$ confidence interval (CI) for the efficacy analysis of effect size, whereas measurement data were used to determine the standardized mean difference. Heterogeneity of the included studies was expressed in terms of $P$ and $I^{2}$. If $P>0.1$ and $I^{2}<50 \%$, the result of the test for heterogeneity was considered not statistically significant, and the fixed effects model was used for meta-analysis. For contrast, the random effects model was also applied to the data when $P \leq 0.1$ and $I^{2} \geq 50 \%$.

\section{Results}

\section{Retrieval results and quality assessment}

We searched 2,970 potentially relevant articles in CNKI, 3,488 in Wan fang, 2,393 in VIP, and two each in PubMed, Springer, the Cochrane Library, and ProQuest. We retrieved 2,274 reports after reading the abstracts, and reports involving animal studies, pharmacological studies, and systems analyses were excluded. After screening the full texts of 663 documents that were selected following application of the inclusion and exclusion criteria, 29 studies on arrhythmia were included, ${ }^{6-34}$ of which nine were on PVC, seven on angina, ${ }^{35-41}$ seven on heart failure, ${ }^{42-48}$ two on viral disorders, ${ }^{49,50}$ and four on climacteric syndrome, ${ }^{51-54}$ as shown in Figure 1 and Table 1.

The quality assessment of the studies was performed by two independent reviewers. Of the 49 studies included (Figure 1 and Table 1), only two studies were found to be of high quality (4 points). ${ }^{6-54}$ The results of specific assessment are presented in Table 1.

\section{Results of meta-analysis}

Meta-analysis of Wenxin keli in the treatment of arrhythmia

Clinical efficacy

There were 29 reports on the use of Wenxin keli in the treatment of arrhythmia, including nine on PVC. The results showed that Wenxin keli exhibited better clinical efficacy in 


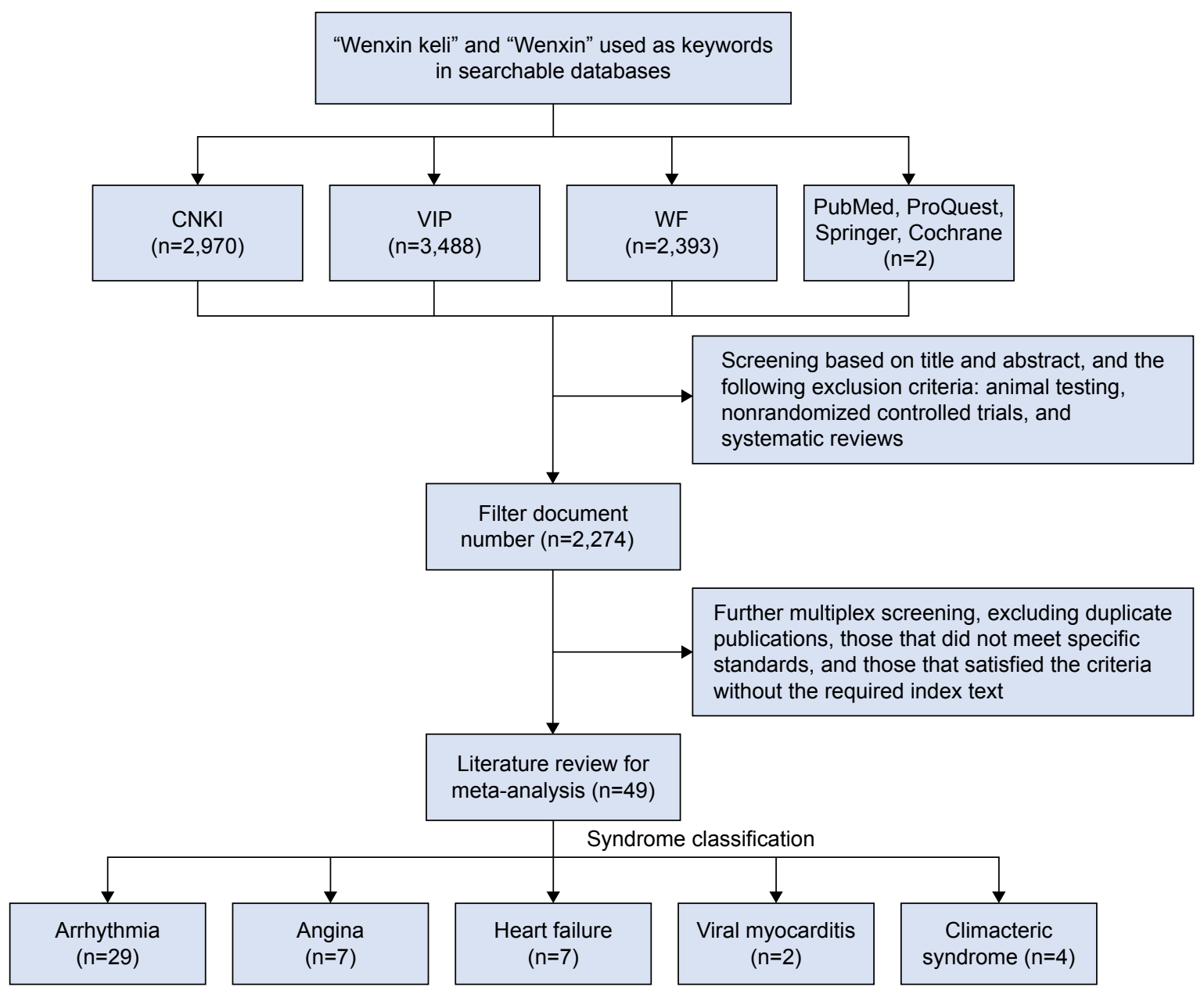

Figure I Study selection steps.

Abbreviations: CNKI, China National Knowledge Infrastructure; VIP, Chinese Scientific Journals Database; WF, Wan fang.

Table I Basic characteristics of included studies

\begin{tabular}{|c|c|c|c|c|c|c|c|}
\hline \multirow[t]{2}{*}{ Study } & \multirow[t]{2}{*}{ Indications } & \multirow{2}{*}{$\begin{array}{l}\text { Number of cases } \\
\text { (test/control groups) }\end{array}$} & \multirow{2}{*}{$\begin{array}{l}\text { Treatment } \\
\text { (days) }\end{array}$} & \multicolumn{2}{|c|}{ Interventions } & \multirow[t]{2}{*}{ Outcomes } & \multirow{2}{*}{$\begin{array}{l}\text { Jadac } \\
\text { score }\end{array}$} \\
\hline & & & & Drug test & Control drug & & \\
\hline $\mathrm{GaO}^{6}$ & Arrhythmia & $48 / 48$ & 28 & Wenxin keli & Propafenone & I, 4 & 2 \\
\hline Liu et $\mathrm{al}^{7}$ & Arrhythmia & $75 / 75$ & 28 & Wenxin keli & Propafenone & 1 & 2 \\
\hline Wang ${ }^{8}$ & Arrhythmia & $60 / 60$ & 28 & Wenxin keli & Propafenone & $\mathrm{I}, 4$ & 2 \\
\hline $\mathrm{Cui}^{9}$ & Arrhythmia & $60 / 60$ & 28 & Wenxin keli & Propafenone & I, 2 & 2 \\
\hline Li et a ${ }^{10}$ & Arrhythmia & $48 / 35$ & 28 & Wenxin keli & Propafenone & I, 2, 3 & 1 \\
\hline$X i e^{\prime \prime}$ & Arrhythmia & $34 / 32$ & 28 & Wenxin keli & Propafenone & I, 4 & 2 \\
\hline Zou and Zhao' ${ }^{12}$ & Arrhythmia & $102 / 101$ & 28 & Wenxin keli & Propafenone & 1 & 2 \\
\hline Wang ${ }^{13}$ & Arrhythmia & $75 / 75$ & 28 & Wenxin keli & Propafenone & $\mathrm{I}, 4$ & 2 \\
\hline Lou $^{14}$ & Arrhythmia & $53 / 50$ & 28 & Wenxin keli & Propafenone & I & 2 \\
\hline Shi ${ }^{15}$ & Arrhythmia & $32 / 30$ & 28 & Wenxin keli & Propafenone & $\mathrm{I}, 4$ & 2 \\
\hline Wang' ${ }^{16}$ & Arrhythmia & $58 / 64$ & 28 & Wenxin keli & Propafenone & 2,4 & 2 \\
\hline Jin and Huang ${ }^{17}$ & Arrhythmia & $20 / 20$ & 28 & Wenxin keli & Propafenone & 3 & 3 \\
\hline$X_{u e^{18}}$ & Arrhythmia & $126 / 72$ & 28 & Wenxin keli & Propafenone & 3 & 3 \\
\hline Ren and Qiao' ${ }^{19}$ & Arrhythmia & $43 / 21$ & 28 & Wenxin keli & Propafenone & 3 & 3 \\
\hline Wu and $Y u e^{20}$ & Arrhythmia & $48 / 33$ & 28 & Wenxin keli & Propafenone & 3 & 2 \\
\hline $\mathrm{Li}$ and Shen ${ }^{21}$ & Arrhythmia & $40 / 37$ & 28 & Wenxin keli & Amiodarone & I, 4 & 2 \\
\hline Wang ${ }^{22}$ & Arrhythmia & $46 / 30$ & 28 & Wenxin keli & Amiodarone & I, 4 & 2 \\
\hline Pang $^{23}$ & Arrhythmia & $56 / 58$ & 28 & Wenxin keli & Amiodarone & I, 4 & 2 \\
\hline Xu et $\mathrm{al}^{24}$ & Arrhythmia & $68 / 61$ & 28 & Wenxin keli & Amiodarone & $\mathrm{I}, 4$ & 2 \\
\hline
\end{tabular}


Table I (Continued)

\begin{tabular}{|c|c|c|c|c|c|c|c|}
\hline \multirow[t]{2}{*}{ Study } & \multirow[t]{2}{*}{ Indications } & \multirow{2}{*}{$\begin{array}{l}\text { Number of cases } \\
\text { (test/control groups) }\end{array}$} & \multirow{2}{*}{$\begin{array}{l}\text { Treatment } \\
\text { (days) }\end{array}$} & \multicolumn{2}{|c|}{ Interventions } & \multirow[t]{2}{*}{ Outcomes } & \multirow{2}{*}{$\begin{array}{l}\text { Jadad } \\
\text { score }\end{array}$} \\
\hline & & & & Drug test & Control drug & & \\
\hline $\mathrm{Xia}^{25}$ & Arrhythmia & $50 / 50$ & 28 & Wenxin keli & Amiodarone & I, 4 & 2 \\
\hline Sun ${ }^{26}$ & PVC & $32 / 31$ & 28 & Wenxin keli & Propafenone & I, 2, 3 & 2 \\
\hline$W_{u^{27}}$ & PVC & $54 / 35$ & 28 & Wenxin keli & Propafenone & I, 2 & 2 \\
\hline Wang ${ }^{28}$ & PVC & $60 / 30$ & 28 & Wenxin keli & Propafenone & I & 2 \\
\hline $\mathrm{Guo}^{29}$ & PVC & $53 / 53$ & 28 & Wenxin keli & Propafenone & I, 2, 3 & 2 \\
\hline $\operatorname{Jin}^{30}$ & PVC & $60 / 30$ & 28 & Wenxin keli & Propafenone & I, 2, 3 & 2 \\
\hline Zhang et $\mathrm{al}^{3 \mathrm{I}}$ & PVC & $39 / 38$ & 28 & Wenxin keli & Propafenone & 2,3 & 2 \\
\hline $\mathrm{Li}^{32}$ & PVC & $32 / 32$ & 28 & Wenxin keli & Propafenone & 3 & 2 \\
\hline Wang 33 & PVC & $60 / 60$ & 28 & Wenxin keli & Propafenone & 2,3 & 2 \\
\hline Yan 34 & PVC & $60 / 60$ & 28 & Wenxin keli & Propafenone & 2,3 & 2 \\
\hline
\end{tabular}

Notes: I, clinical efficacy; 2, ECG efficacy; 3, clinical symptoms of heart palpitations, shortness of breath, dizziness, insomnia, chest tightness, etc; 4 , adverse reactions.

\begin{tabular}{|c|c|c|c|c|c|c|c|}
\hline Yu et $\mathrm{al}^{35}$ & Angina & $40 / 35$ & 28 & $\begin{array}{l}\text { Conventional treatment }+ \\
\text { Wenxin keli }\end{array}$ & Conventional treatment & $\mathrm{I}, 2$ & 2 \\
\hline Shu and $\mathrm{Li}^{36}$ & Angina & $37 / 37$ & 28 & $\begin{array}{l}\text { Conventional treatment }+ \\
\text { Wenxin keli }\end{array}$ & Conventional treatment & I & 2 \\
\hline Ye et $\mathrm{al}^{37}$ & Angina & $36 / 36$ & 28 & $\begin{array}{l}\text { Conventional treatment }+ \\
\text { Wenxin keli }\end{array}$ & Conventional treatment & $\mathrm{I}, 2$ & 2 \\
\hline Wei et $\mathrm{al}^{38}$ & Angina & $50 / 50$ & 28 & $\begin{array}{l}\text { Conventional treatment }+ \\
\text { Wenxin keli }\end{array}$ & Conventional treatment & $\mathrm{I}, 2$ & 2 \\
\hline Yuan 39 & $\begin{array}{l}\text { Unstable } \\
\text { angina }\end{array}$ & $47 / 47$ & 28 & $\begin{array}{l}\text { Conventional treatment }+ \\
\text { Wenxin keli }\end{array}$ & Conventional treatment & $\mathrm{I}, 4$ & 2 \\
\hline $\begin{array}{l}\text { Wei and } \\
\text { Deng }\end{array}$ & $\begin{array}{l}\text { Unstable } \\
\text { angina }\end{array}$ & $50 / 50$ & 28 & $\begin{array}{l}\text { Conventional treatment }+ \\
\text { Wenxin keli }\end{array}$ & Conventional treatment & $\mathrm{I}, 3$ & 2 \\
\hline Yuan and $\mathrm{Wei}^{4 \mathrm{I}}$ & $\begin{array}{l}\text { Unstable } \\
\text { angina }\end{array}$ & $80 / 80$ & 28 & $\begin{array}{l}\text { Conventional treatment }+ \\
\text { Wenxin keli }\end{array}$ & Conventional treatment & I, 3, 4 & 2 \\
\hline
\end{tabular}

Notes: I, angina pectoris; 2, ECG efficacy; 3, changes in the indicator lipids; 4, adverse reactions.

\begin{tabular}{|c|c|c|c|c|c|c|c|}
\hline Yu et $\mathrm{al}^{42}$ & $\begin{array}{l}\text { Chronic } \\
\text { heart failure }\end{array}$ & $37 / 35$ & 56 & $\begin{array}{l}\text { Conventional treatment }+ \\
\text { Wenxin keli }\end{array}$ & Conventional treatment & I, 2, 3 & 4 \\
\hline $\begin{array}{l}\text { Yang and } \\
\text { Dong }^{43}\end{array}$ & $\begin{array}{l}\text { Chronic } \\
\text { heart failure }\end{array}$ & $40 / 40$ & 56 & $\begin{array}{l}\text { Conventional treatment }+ \\
\text { Wenxin keli }\end{array}$ & Conventional treatment & $\mathrm{I}, 3,4$ & 2 \\
\hline Kong et $\mathrm{al}^{44}$ & $\begin{array}{l}\text { Chronic } \\
\text { heart failure }\end{array}$ & $30 / 30$ & 56 & $\begin{array}{l}\text { Conventional treatment }+ \\
\text { Wenxin keli }\end{array}$ & Conventional treatment & $2,4,6$ & 2 \\
\hline $\mathrm{Xu}^{45}$ & $\begin{array}{l}\text { Chronic } \\
\text { heart failure }\end{array}$ & $37 / 35$ & 56 & $\begin{array}{l}\text { Conventional treatment }+ \\
\text { Wenxin keli }\end{array}$ & Conventional treatment & 3 & 4 \\
\hline $\mathrm{Hu}^{46}$ & $\begin{array}{l}\text { Chronic } \\
\text { heart failure }\end{array}$ & $50 / 48$ & 56 & $\begin{array}{l}\text { Conventional treatment }+ \\
\text { Wenxin keli }\end{array}$ & Conventional treatment & 4 & 2 \\
\hline$Y_{u^{47}}$ & $\begin{array}{l}\text { Congestive } \\
\text { heart failure }\end{array}$ & $35 / 37$ & 56 & $\begin{array}{l}\text { Conventional treatment }+ \\
\text { Wenxin keli }\end{array}$ & Conventional treatment & $I, 2,3,5$ & 2 \\
\hline Wang $^{48}$ & $\begin{array}{l}\text { Congestive } \\
\text { heart failure }\end{array}$ & $35 / 35$ & 56 & $\begin{array}{l}\text { Conventional treatment }+ \\
\text { Wenxin keli }\end{array}$ & Conventional treatment & $1,2,4,6,7$ & 2 \\
\hline
\end{tabular}

Notes: I, clinical efficacy; 2, TCM syndromes; 3, clinical echocardiography; 4, plasma BNP values; 5, heart rate; 6, 6-minute walking distance measurement; 7, adverse reactions.

\begin{tabular}{|c|c|c|c|c|c|c|c|}
\hline Yang ${ }^{49}$ & $\begin{array}{l}\text { Children } \\
\text { with viral } \\
\text { myocarditis }\end{array}$ & $34 / 34$ & 14 & $\begin{array}{l}\text { Conventional treatment }+ \\
\text { Wenxin keli }\end{array}$ & Conventional treatment & I, 2 & 2 \\
\hline Deng $^{50}$ & $\begin{array}{l}\text { Children } \\
\text { with viral } \\
\text { myocarditis }\end{array}$ & $30 / 28$ & 14 & $\begin{array}{l}\text { Conventional treatment }+ \\
\text { Wenxin keli }\end{array}$ & Conventional treatment & I & 2 \\
\hline Liu and $\operatorname{Ren}^{51}$ & $\begin{array}{l}\text { Climacteric } \\
\text { syndrome }\end{array}$ & $60 / 58$ & 84 & $\begin{array}{l}\text { Conventional treatment }+ \\
\text { Wenxin keli }\end{array}$ & $\begin{array}{l}\text { Conventional treatment }+ \\
\text { metoprolol }\end{array}$ & I & 2 \\
\hline $\operatorname{Lei}^{52}$ & $\begin{array}{l}\text { Climacteric } \\
\text { syndrome }\end{array}$ & $42 / 38$ & 84 & $\begin{array}{l}\text { Conventional treatment }+ \\
\text { Wenxin keli }\end{array}$ & $\begin{array}{l}\text { Conventional treatment }+ \\
\text { metoprolol }\end{array}$ & I & 2 \\
\hline $\mathrm{Li}$ and $\mathrm{Miao}^{53}$ & $\begin{array}{l}\text { Climacteric } \\
\text { syndrome }\end{array}$ & $33 / 33$ & 60 & Wenxin keli & $\begin{array}{l}\text { Oryzanol + propranolol + } \\
\text { vitamin B complex }\end{array}$ & I & 2 \\
\hline $\mathrm{Hu}^{54}$ & $\begin{array}{l}\text { Climacteric } \\
\text { syndrome }\end{array}$ & $25 / 23$ & 60 & Wenxin keli & $\begin{array}{l}\text { Oryzanol + propranolol + } \\
\text { vitamin B complex }\end{array}$ & I & 2 \\
\hline
\end{tabular}

Notes: I, clinical efficacy; 2, adverse reactions.

Abbreviations: BNP, brain natriuretic peptide; CK-MB, creatine kinase MB isoenzyme; ECG, electrocardiogram; PVC, premature ventricular contractions; TCM, traditional Chinese medicine. 
the treatment of arrhythmia $(\mathrm{OR}=1.74,95 \% \mathrm{CI}[1.28,2.35]$, $P=0.0003$; Figure 2) compared to propafenone. Also, in comparison to amiodarone, Wenxin keli again exhibited better clinical efficacy in the treatment of arrhythmia (OR $=2.28,95 \%$ CI [1.33, 3.89], $P=0.003$; Figure 3).

Five studies considered the use of Wenxin keli in the treatment of PVC. The meta-analysis showed that it exhibited better clinical efficacy than propafenone $(\mathrm{OR}=2.92,95 \% \mathrm{CI}$ [1.72, 4.96], $P<0.0001$; Figure 4).

\section{Efficacy of Wenxin keli on electrocardiogram}

Three studies reported on the efficacy of Wenxin keli on electrocardiogram (ECG). Meta-analysis of the random effects model showed no significant difference between Wenxin keli and propafenone in the treatment of arrhythmia based on the ECG $(\mathrm{OR}=2.15,95 \%$ CI $[0.58,7.97], P=0.25$; Figure 5).

Eight studies reported on the use of Wenxin keli in the treatment of PVC. The meta-analysis showed that Wenxin keli showed better efficacy than propafenone based on the ECG (OR $=2.19,95 \%$ CI $[1.45,3.30], P=0.0002$; Figure 6).

\section{Secondary outcomes}

Five studies reported on the effect of Wenxin keli treatment on secondary efficacy variables in PVC. Heterogeneity was minimal; thus, the fixed effects model was applied to the study that reported on secondary efficacy variables, in addition to dizziness. The results showed that Wenxin keli exhibited better efficacy, in addition to dizziness (Table 2).

\section{Adverse reactions}

A total of eleven studies reported adverse reactions in the treatment of arrhythmia. Wenxin keli showed a lower incidence of adverse reactions, with reports of mild adverse reactions and favorable clinical application and safety, in comparison to both propafenone and amiodarone (Figures 7 and 8).

Six studies reported on adverse reactions in the treatment of PVC. Meta-analysis of the fixed effects model showed that Wenxin keli exhibited a lower incidence of adverse reactions $(\mathrm{OR}=0.32,95 \% \mathrm{CI}[0.16,0.64], P=0.001$; Figure 9) compared to amiodarone.

\section{Publication bias}

A funnel plot (Figure 10) showed that the studies reporting the use of Wenxin keli in the treatment of arrhythmia, included in the analysis, were substantially symmetric. This suggests less publication bias in these reports. According to the Cochrane Handbook, funnel plot analysis should not be performed for other indications if there are less than ten studies.

\section{Meta-analysis of Wenxin keli in the treatment of angina}

Angina pectoris

Six reports, included in the analysis, reported on the use of Wenxin keli in the treatment of angina pectoris, of which three specifically focused on angina and three on unstable angina. Meta-analysis of the fixed effects model showed that the clinical efficacy of Wenxin keli combined with conventional therapy in the treatment of angina was significantly better than conventional therapy alone $(\mathrm{OR}=3.12,95 \% \mathrm{CI}[1.77$, 5.52], $P<0.0001$; Figure 11). The clinical efficacy of Wenxin keli combined with conventional therapy in the treatment of unstable angina was also significantly better than conventional therapy alone $(\mathrm{OR}=3.97,95 \%$ CI $[1.92,8.22]$, $P=0.0002$; Figure 12).

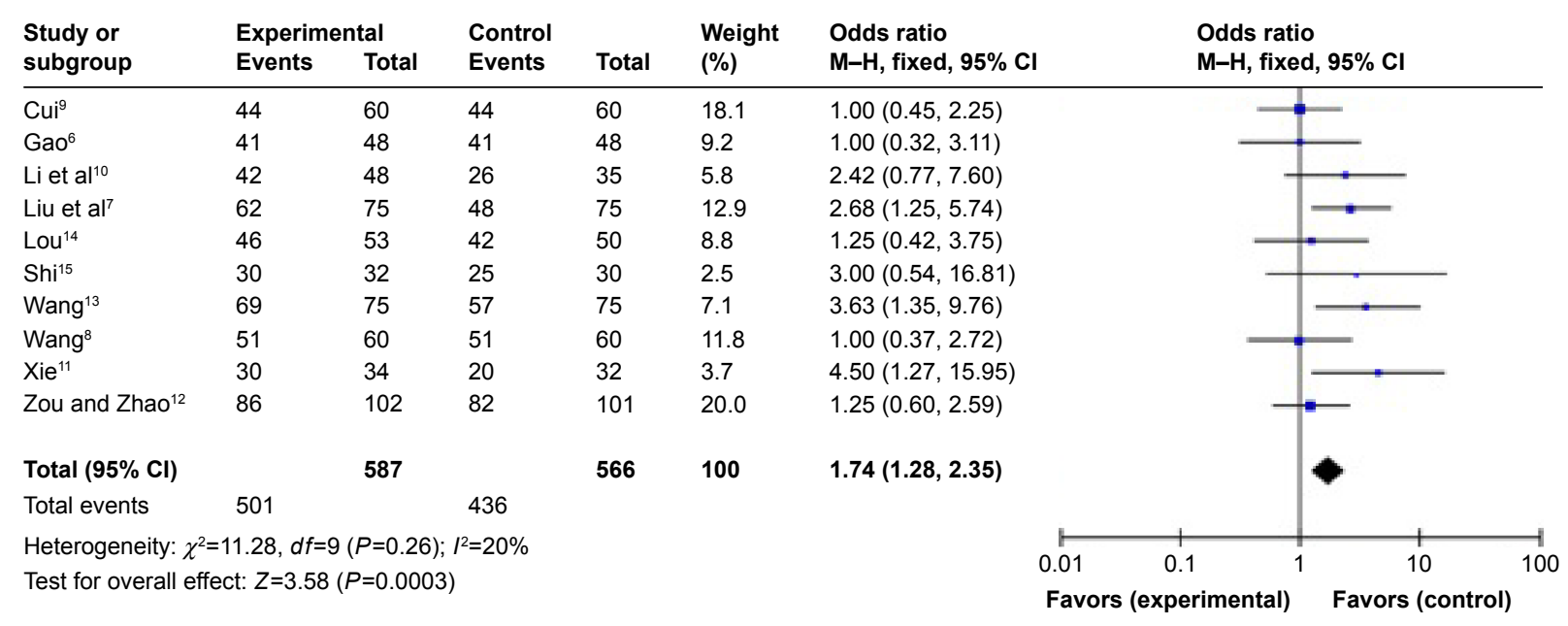

Figure 2 Meta-analysis of Wenxin keli and propafenone in the treatment of arrhythmia. Abbreviations: $\mathrm{Cl}$, confidence interval; $\mathrm{M}-\mathrm{H}$, Mantel-Haenszel. 


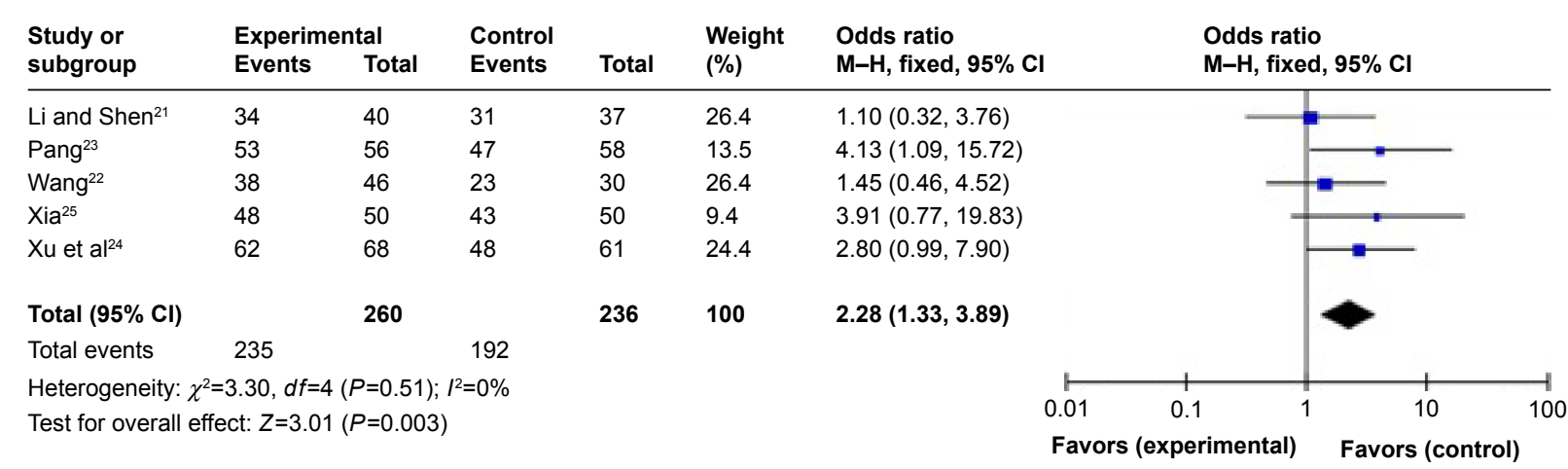

Figure 3 Meta-analysis of Wenxin keli and amiodarone in the treatment of arrhythmia.

Abbreviations: $\mathrm{Cl}$, confidence interval; $\mathrm{M}-\mathrm{H}$, Mantel-Haenszel.

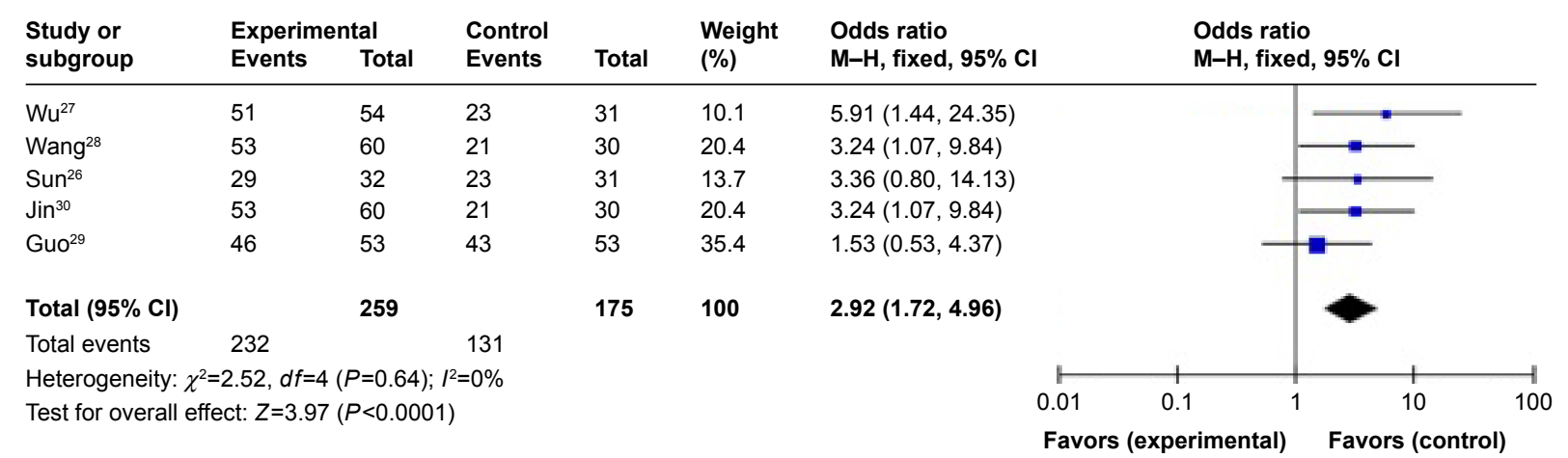

Figure 4 Meta-analysis of Wenxin keli and propafenone in the treatment of PVC.

Abbreviations: $\mathrm{Cl}$, confidence interval; PVC, premature ventricular contractions; $\mathrm{M}-\mathrm{H}$, Mantel-Haenszel.

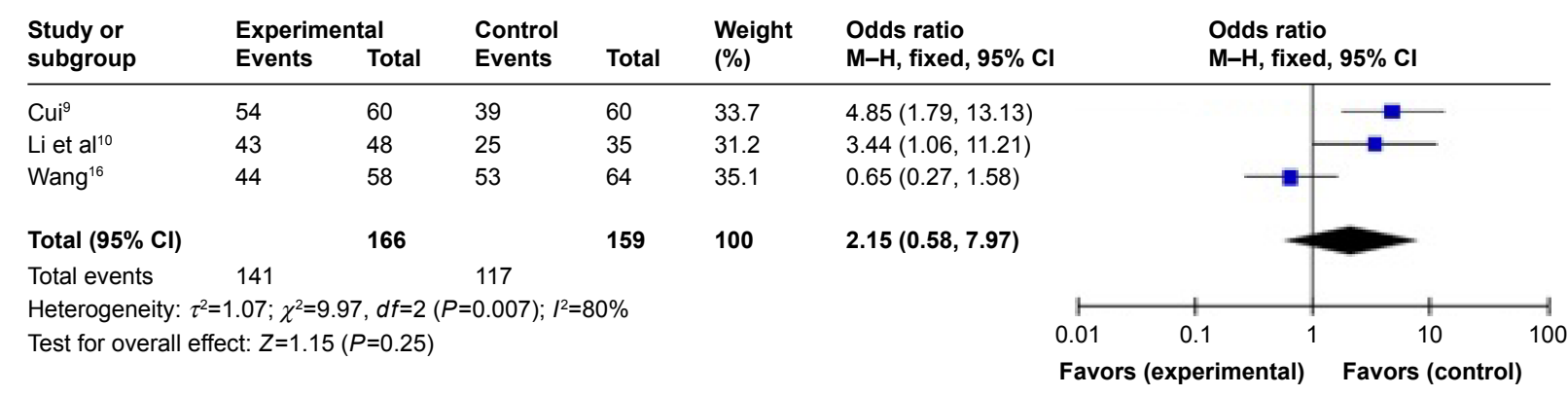

Figure 5 Meta-analysis of Wenxin keli and propafenone in the treatment of arrhythmia.

Abbreviations: $\mathrm{Cl}$, confidence interval; $\mathrm{M}-\mathrm{H}$, Mantel-Haenszel.

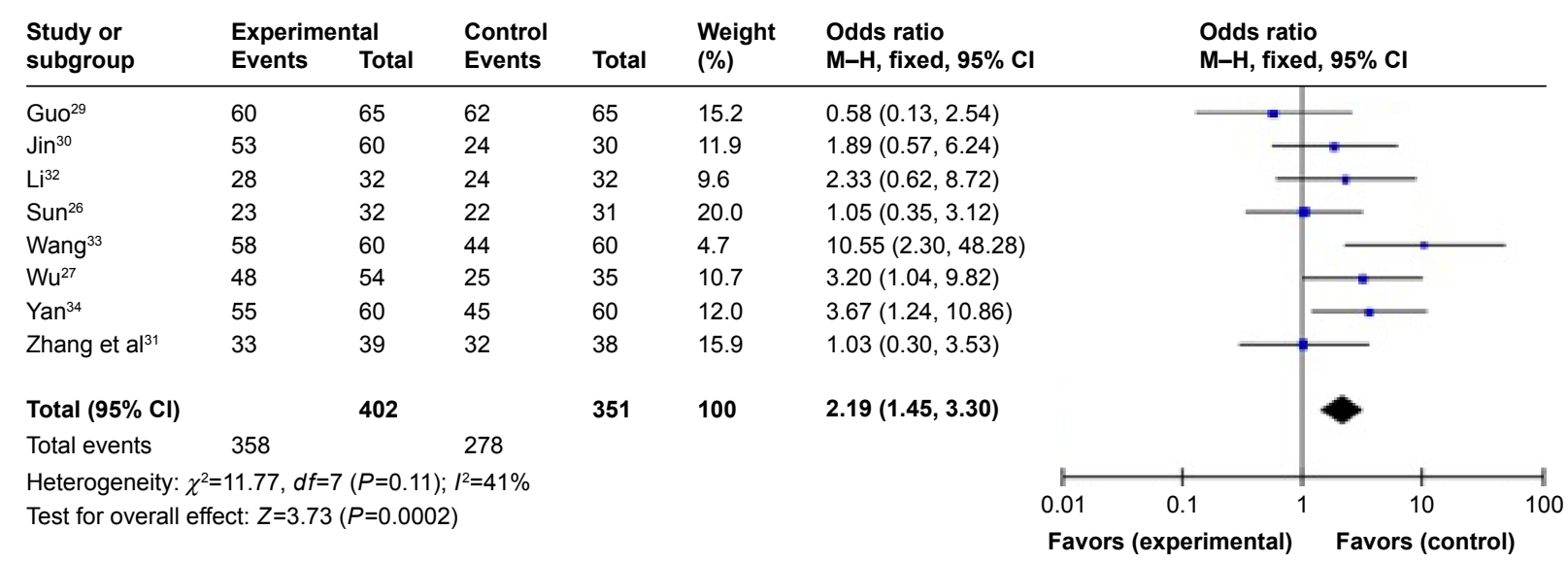

Figure 6 Meta-analysis of Wenxin keli and propafenone in the treatment of PVC.

Abbreviations: $\mathrm{Cl}$, confidence interval; PVC, premature ventricular contractions; $\mathrm{M}-\mathrm{H}$, Mantel-Haenszel. 
Table 2 Meta-analysis of secondary efficacy variables in treatment of arrhythmia

\begin{tabular}{|c|c|c|c|c|c|c|c|}
\hline \multirow[t]{2}{*}{ Outcomes } & \multirow{2}{*}{$\begin{array}{l}\text { Number of } \\
\text { included studies }\end{array}$} & \multirow{2}{*}{$\begin{array}{l}\text { Number } \\
\text { of cases }\end{array}$} & \multicolumn{2}{|c|}{ Heterogeneity } & \multirow[t]{2}{*}{ Model } & \multicolumn{2}{|l|}{ Meta-analysis } \\
\hline & & & $I^{2}$ & $P$-value & & OR (95\% Cl) & $P$-value \\
\hline Palpitations & 4 & 383 & $0 \%$ & 0.99 & Fixed & $3.29(\mathrm{I} .64,6.6 \mathrm{I})$ & 0.0008 \\
\hline Chest tightness & 5 & 451 & $0 \%$ & 0.70 & Fixed & $3.6 \mathrm{I}(2.22,5.87)$ & $<0.00001$ \\
\hline Restless sleep & 4 & 373 & $0 \%$ & 0.50 & Fixed & $2.49(1.40,4.43)$ & 0.002 \\
\hline Dizziness & 4 & 379 & $55 \%$ & 0.09 & Random & $2.53(0.87,7.35)$ & 0.09 \\
\hline Shortness of breath & 5 & 462 & $0 \%$ & 0.94 & Fixed & $3.00(1.74,5.19)$ & $<0.0001$ \\
\hline
\end{tabular}

Abbreviations: $\mathrm{Cl}$, confidence interval; $\mathrm{OR}$, odds ratio.

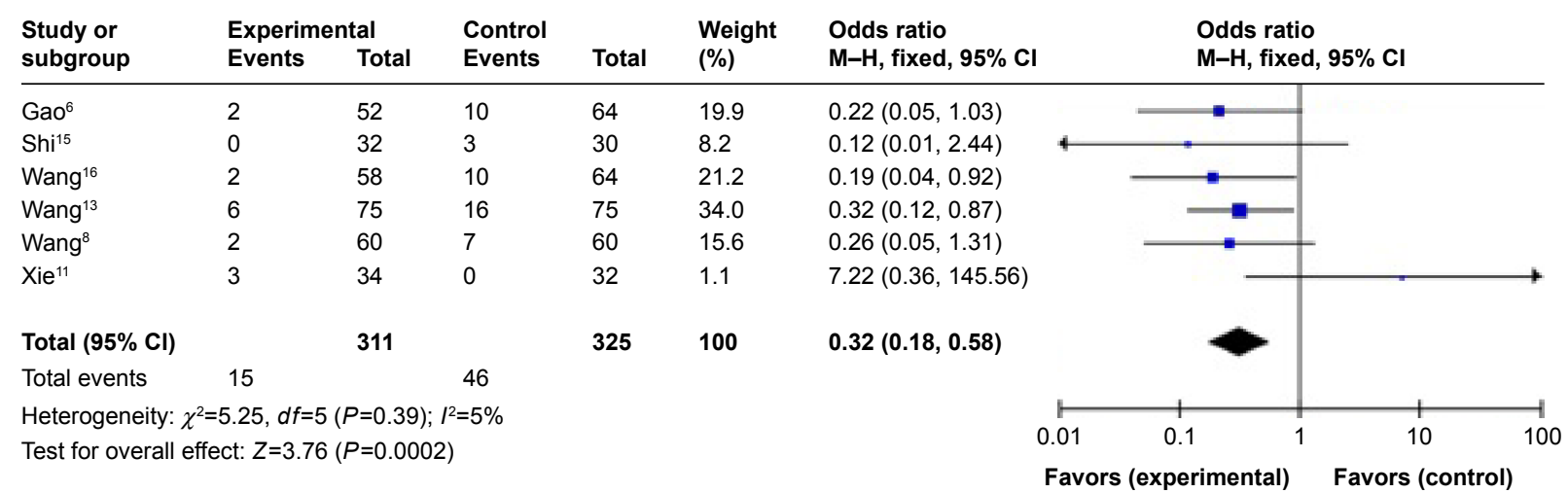

Figure 7 Meta-analysis of Wenxin keli, propafenone, and associated adverse reactions on arrhythmia.

Abbreviations: $\mathrm{Cl}$, confidence interval; $\mathrm{M}-\mathrm{H}$, Mantel-Haenszel.

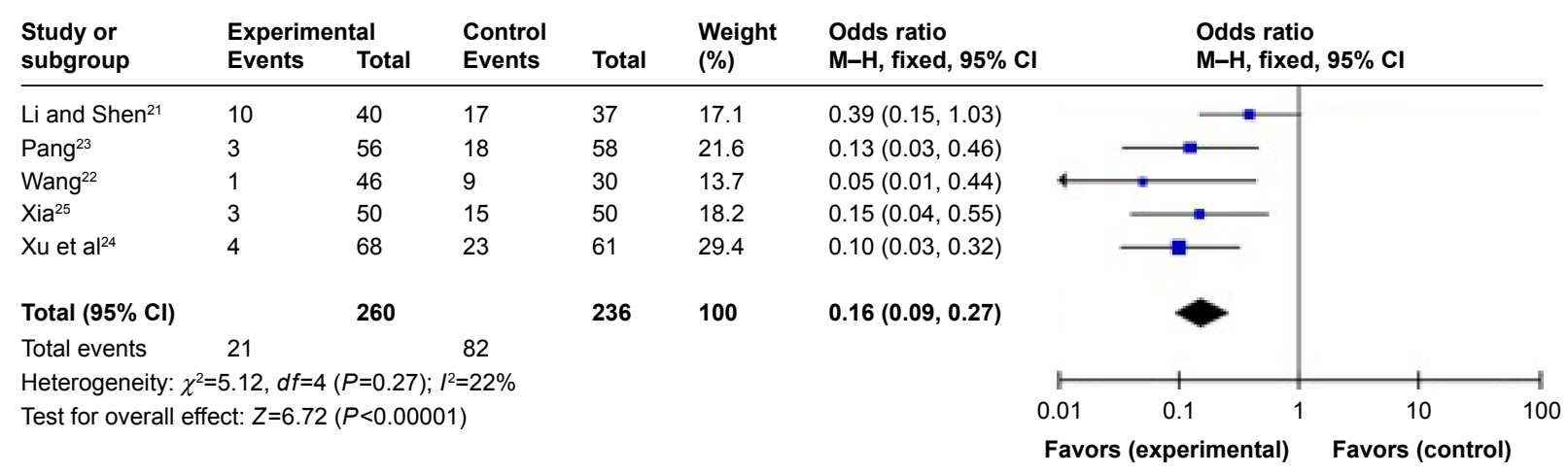

Figure 8 Meta-analysis of Wenxin keli, amiodarone, and associated adverse reactions on arrhythmia. Abbreviations: $\mathrm{Cl}$, confidence interval; $\mathrm{M}-\mathrm{H}$, Mantel-Haenszel.

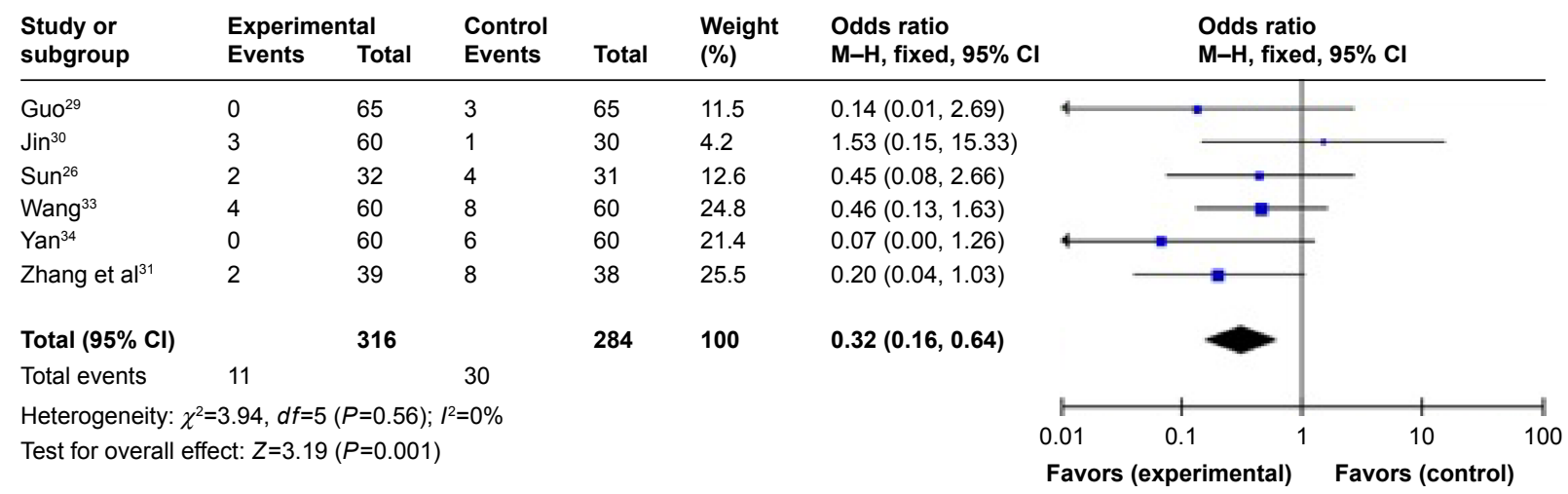

Figure 9 Meta-analysis of Wenxin keli, propafenone, and associated adverse reactions on PVC.

Abbreviations: $\mathrm{Cl}$, confidence interval; $\mathrm{M}-\mathrm{H}$, Mantel-Haenszel. 


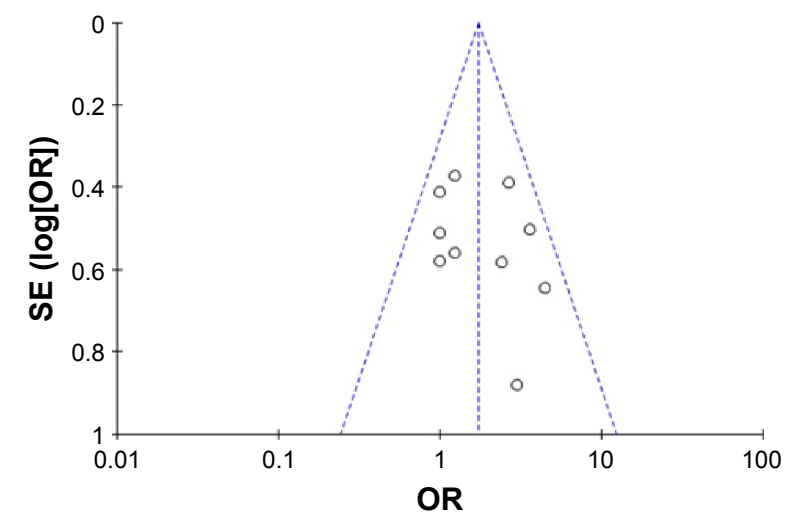

Figure 10 Funnel plot of Wenxin keli and propafenone in the treatment of arrhythmia.

Abbreviations: SE, standard error of the mean; OR, odds ratio.

\section{ECG efficacy}

Two studies reported on the efficacy of Wenxin keli in the treatment of angina based on the ECG. Meta-analysis of the fixed effects model showed that the efficacy of Wenxin keli combined with conventional therapy was not significantly different from that of the conventional therapy alone ( $\mathrm{OR}=2.02,95 \%$ CI $[0.65,6.24], P=0.22$; Figure 13 ).

\section{Adverse reactions}

Three studies mentioned the development of adverse reactions to Wenxin keli in the treatment of angina, two of which could not be compared because the experimental and control groups were not described separately. The latter test group and six cases (15\%) in the control group exhibited no adverse reactions.

Meta-analysis of Wenxin keli in the treatment of heart failure

\section{Clinical efficacy}

Two studies reported on the clinical efficacy of Wenxin keli in the treatment of chronic heart failure. Meta-analysis showed that Wenxin keli combined with conventional treatment showed no greater clinical efficacy $(\mathrm{OR}=2.62$, $95 \%$ CI $[0.91,7.56], P=0.07$; Figure 14) compared to the conventional treatment group.

\section{Secondary efficacy variables}

Analysis of secondary efficacy end points showed that Wenxin keli combined with conventional treatment showed better efficacy in left ventricular ejection fraction (LVEF) values, plasma brain natriuretic peptide (BNP) levels, and stroke volume (Table 3).

\section{Meta-analysis of Wenxin keli in the treatment}

of viral infections

Clinical efficacy

Two studies reported on the clinical efficacy of Wenxin keli in the treatment of viral infections. Meta-analysis showed that Wenxin keli combined with conventional treatment exhibited better clinical efficacy $(\mathrm{OR}=4.89,95 \%$ CI $[1.30,18.38]$, $P=0.02$; Figure 15) compared to conventional treatment.

\section{Adverse reactions}

Two studies investigated adverse reactions associated with Wenxin keli in the treatment of viral infections. No adverse reactions were reported in either study, suggesting the safety of Wenxin keli.

\section{Meta-analysis of Wenxin keli in the treatment}

of climacteric syndrome

\section{Clinical efficacy}

Four studies reported on the clinical efficacy of Wenxin keli in the treatment of climacteric syndrome, of which two compared Wenxin keli combined with conventional therapy to conventional therapy alone, and the other two compared Wenxin keli to a combination of oryzanol, propranolol, and vitamin B complex. Meta-analysis showed that in comparison to conventional treatment alone, Wenxin keli combined

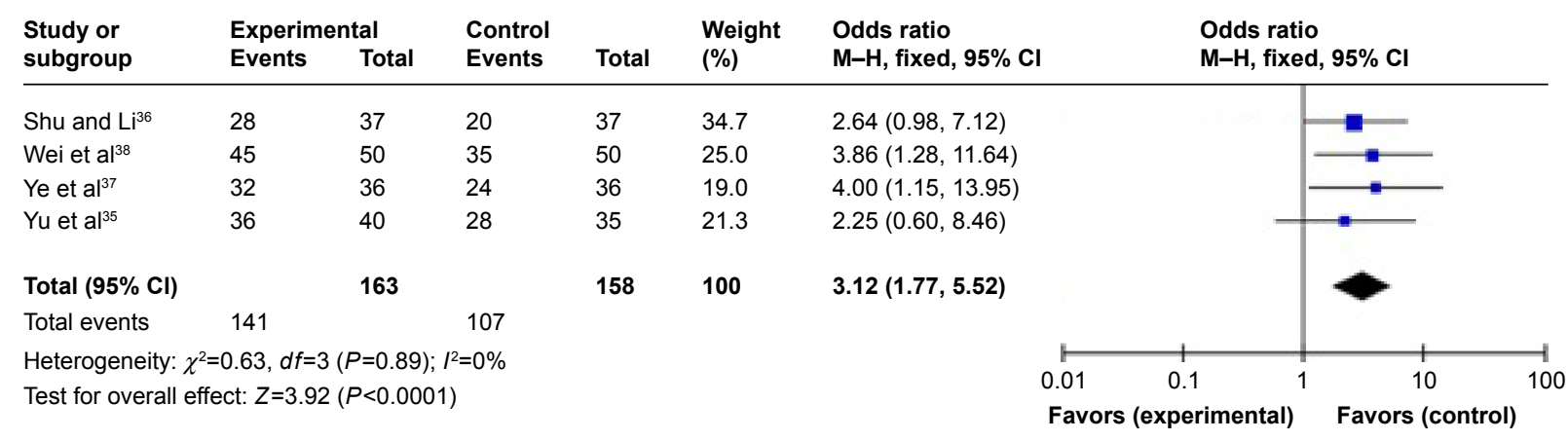

Figure I I Meta-analysis of Wenxin keli and propafenone in the treatment of angina. Abbreviations: $\mathrm{Cl}$, confidence interval; $\mathrm{M}-\mathrm{H}$, Mantel-Haenszel. 


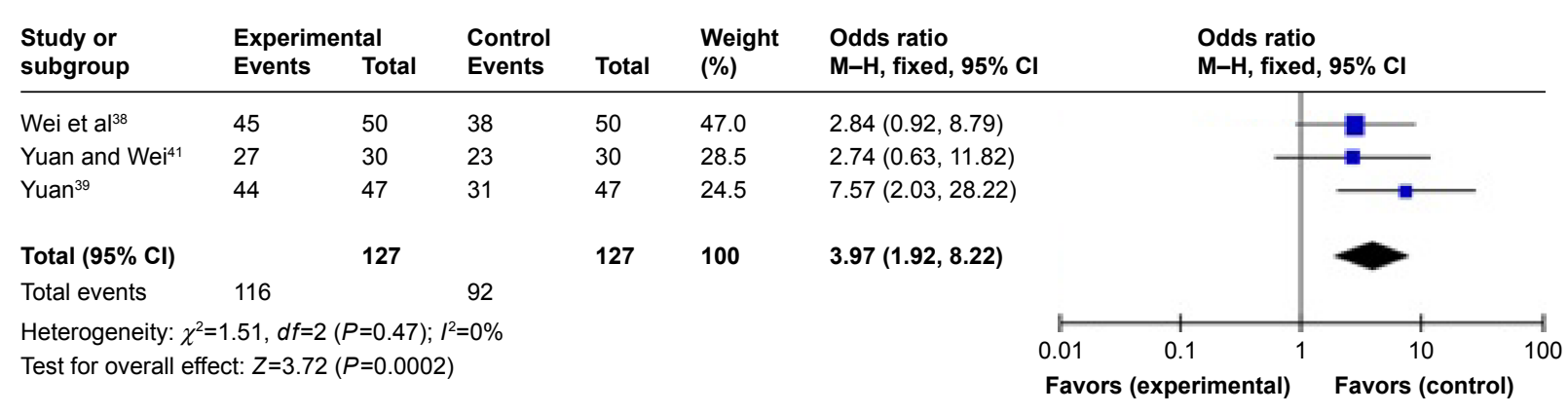

Figure 12 Meta-analysis of Wenxin keli and propafenone in the treatment of unstable angina. Abbreviations: $\mathrm{Cl}$, confidence interval; $\mathrm{M}-\mathrm{H}$, Mantel-Haenszel.

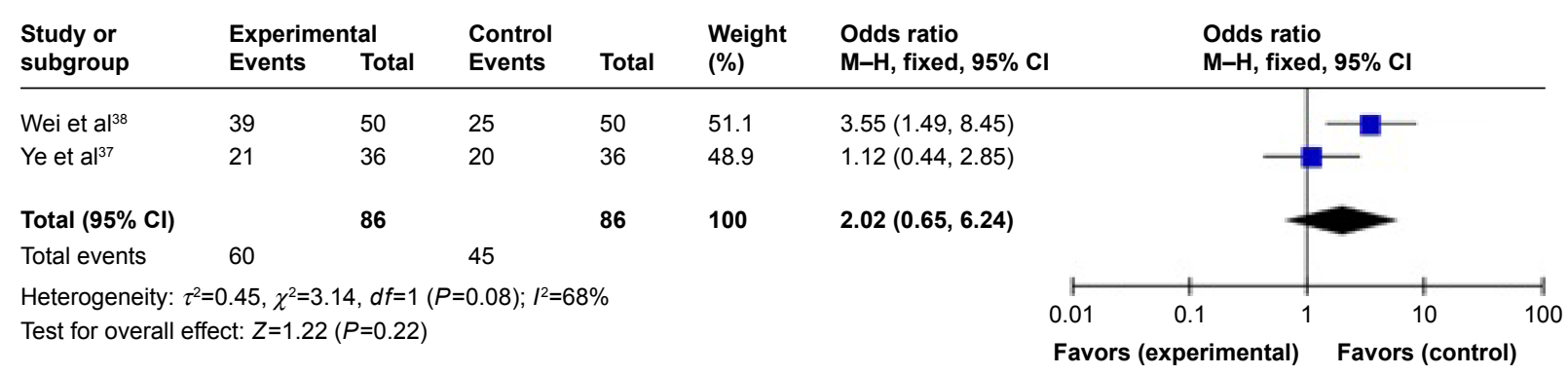

Figure 13 Meta-analysis of Wenxin keli combined with conventional therapy in the treatment of angina. Abbreviations: $\mathrm{Cl}$, confidence interval; $\mathrm{M}-\mathrm{H}$, Mantel-Haenszel.

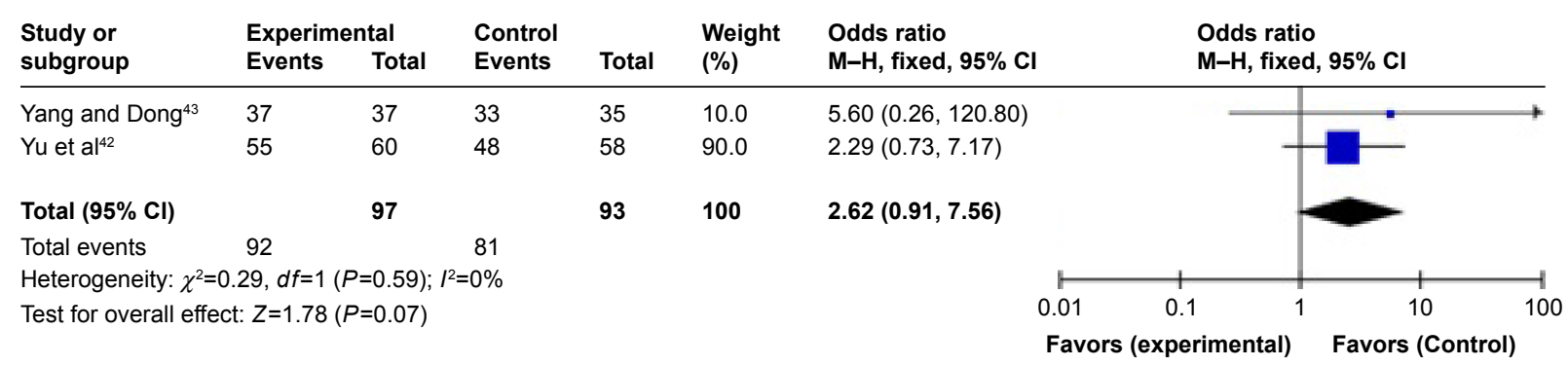

Figure 14 Meta-analysis of Wenxin keli combined with conventional treatment for chronic heart failure. Abbreviations: $\mathrm{Cl}$, confidence interval; $\mathrm{M}-\mathrm{H}$, Mantel-Haenszel.

Table 3 Meta-analysis of secondary efficacy variables in treatment of heart failure

\begin{tabular}{|c|c|c|c|c|c|c|c|}
\hline \multirow[t]{2}{*}{ Outcomes } & \multirow{2}{*}{$\begin{array}{l}\text { Number of } \\
\text { included studies }\end{array}$} & \multirow{2}{*}{$\begin{array}{l}\text { Number } \\
\text { of cases }\end{array}$} & \multicolumn{2}{|c|}{ Heterogeneity } & \multirow[t]{2}{*}{ Model } & \multicolumn{2}{|l|}{ Meta-analysis } \\
\hline & & & $I^{2}$ & $P$-value & & MD (95\% Cl) & $P$-value \\
\hline LVEF values & 4 & 310 & $57 \%$ & 0.08 & Random & $0.76(0.41,1.12)$ & $<0.0001$ \\
\hline Plasma BNP levels & 3 & 238 & $99 \%$ & $<0.0000 \mathrm{I}$ & Random & $-5.92(-9.70,-2.14)$ & 0.002 \\
\hline Stroke volume & 3 & 212 & $29 \%$ & 0.24 & Fixed & $0.50(0.18,0.83)$ & 0.002 \\
\hline
\end{tabular}

Abbreviations: BNP, brain natriuretic peptide; $\mathrm{Cl}$, confidence interval; LVEF, left ventricular ejection fraction; MD, mean difference.

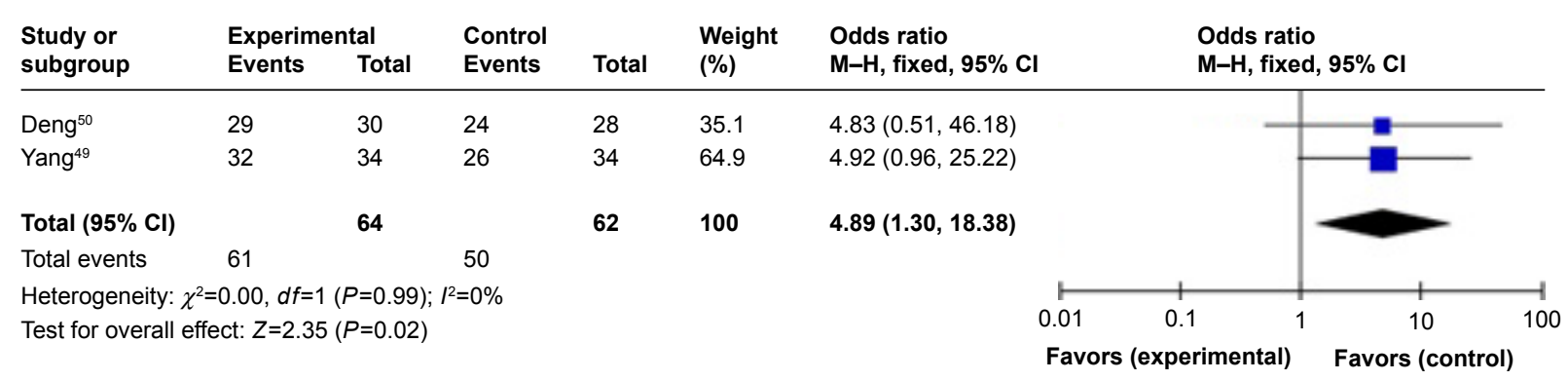

Figure 15 Meta-analysis of Wenxin keli combined with conventional treatment for viral infections.

Abbreviations: $\mathrm{Cl}$, confidence interval; $\mathrm{M}-\mathrm{H}$, Mantel-Haenszel. 


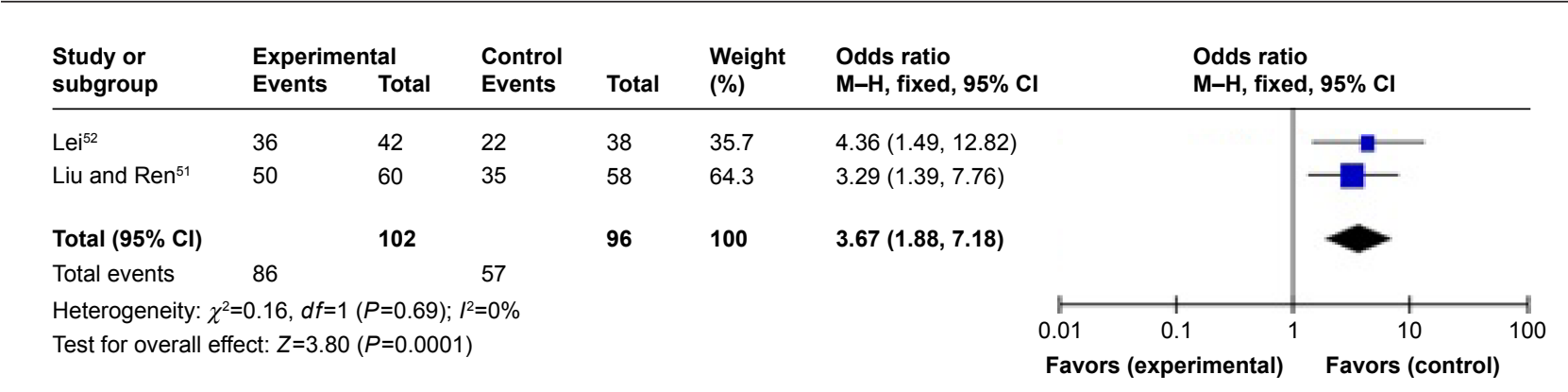

Figure 16 Meta-analysis of Wenxin keli combined with conventional treatment for climacteric syndrome. Abbreviations: $\mathrm{Cl}$, confidence interval; $\mathrm{M}-\mathrm{H}$, Mantel-Haenszel.

with conventional treatment exhibited better clinical efficacy in the treatment of climacteric syndrome (OR $=3.67,95 \%$ CI $1.88,7.18, P=0.0001 ;$ Figure 16 ). In comparison to the control drug (propranolol + oryzanol + vitamin B), Wenxin keli showed better clinical efficacy $(\mathrm{OR}=7.82,95 \%$ CI [2.92, 20.95], $P<0.0001$; Figure 17).

\section{Adverse reactions}

No adverse reactions were reported in the literature regarding the use of Wenxin keli in the treatment of climacteric syndrome. Thus, comparisons between any control and corresponding experimental groups were not possible.

\section{Discussion}

Wenxin keli consists primarily of Codonopsis, Huang Jing, Panax, amber, nard, and other traditional Chinese herbs. It represents the first broad-spectrum treatment capable of affecting multiple ion channels $\left(\mathrm{Na}^{+}, \mathrm{K}^{+}\right.$, and $\left.\mathrm{Ca}^{2+}\right)$ that can also significantly improve heart function (without causing arrhythmias), heart palpitations, chest tightness, and other associated symptoms. Modern pharmacological studies have confirmed that Codonopsis contains inulin and amino acids, and that it exerts anti-platelet aggregation, enhances immunity, and improves myocardial contractile effects. ${ }^{55}$ Huang Jing exhibits lipid-lowering and antiatherosclerotic effect, reduces blood pressure, and increases coronary blood flow. ${ }^{56}$ Panax can increase coronary blood flow, inhibit self-discipline of the ectopic pacemaker sinus node, reduce myocardial oxygen consumption, improve microcirculation, and regulate myocardial ischemia and hypoxia. ${ }^{56}$ Nard plays a role in relieving depression, and pharmacological experiments show that it contains valerian ketones. These compounds can combine with specific proteins via ion channels in the myocardial cell membrane to reduce myocardial cell automaticity, extend the atrial action potential of ventricular muscle and conduction system time, interrupt reentry, and eliminate arrhythmias. ${ }^{57}$ The therapeutic index of Wenxin keli on the heart, kidneys, and liver was within normal limits. Wenxin keli can enhance immune function, without causing significant adverse reactions, and shows no evidence of the side effects of myocardial ischemia and arrhythmia. It is therefore considered to be safe and effective. ${ }^{3}$

\section{Limitations}

Among the studies included in the meta-analysis, only two of them that had higher scores on the Jadad questionnaire were used to evaluate the quality, thereby potentially affecting the strength of the results. There were fewer documents available for some of the indications analyzed, and some studies had smaller sample sizes. Both of these factors represent limitations of the present study. No standards for RCTs have been published in People's Republic of China; therefore, allocation concealment and blinding were rarely mentioned in the studies included in the analysis. Thus, it is possible that most of the original

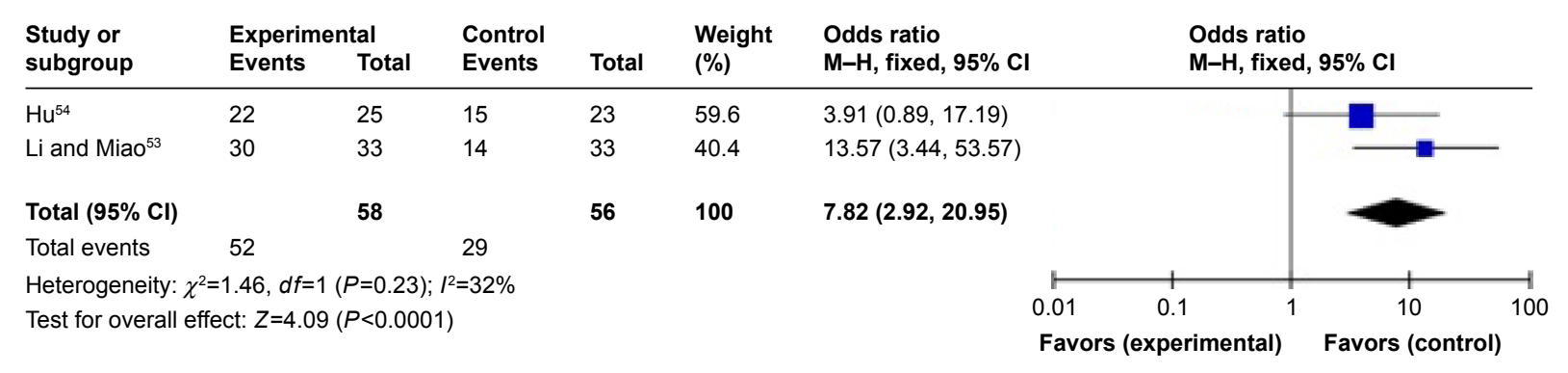


reports were inconclusive and the results were of low quality, thereby increasing bias. To address the aforementioned limitations and verify the results of the present study, additional high-quality RCT studies that employ larger sample sizes are required.

\section{Conclusion}

Based on the available evidence, meta-analysis is an effective method to prove the safety and efficacy of a particular treatment. The results of meta-analysis allow physicians and patients to choose the most effective treatment.

For systematic reviews of Wenxin keli in the treatment of cardiovascular disease, we used the indicators of angina pectoris total efficiency, ECG total efficiency, and adverse outcomes for comparison with the control groups that were treated with propafenone and amiodarone. The findings observed in the treatment of arrhythmia, PVC, angina pectoris, heart failure, viral myocarditis, and climacteric syndrome, among others, were derived from 49 studies. Overall, these studies reported favorable effects of Wenxin keli, regardless of whether it was used directly or as an adjuvant therapy. Furthermore, a low incidence of adverse reactions was evident among the studies analyzed.

\section{Disclosure}

The authors report no conflicts of interest in this work.

\section{References}

1. Go AS, Mozaffarian D, Roger VL, et al. Heart disease and stroke statistics - 2014 update: a report from the American Heart Association. Circulation. 2014;129(3):399-410.

2. World Health Organization. Global Status Report on Noncommunicable Diseases 2010. Geneva: WHO; 2011.

3. Wang J, Shui LM. 1991-2003 Ningbo City Jiangdong district residents cardiovascular disease mortality dynamic analysis. Chin J Prevent Control Chronic Dis. 2005;13(5):251-252.

4. Hu XL, Zhou JM, Chen XP. Role of AGXT2 in ADMA metabolism and the development of cardiovascular and cerebrovascular diseases. Chin Pharmacol Bull. 2015;05:601-605.

5. Li YH, Zhou JM, Yang C, et al. Study on cardiovaseular and cerebrovaseular diseases and its influencing factors among 5 kinds of occupational populations in 6 provinces in China. Chin J Health Education 2012;01:3-7.

6. Gao P. Clinical analysis of 52 cases buchang Wenxin keli in treatment of arrhythmia. Chin Comm Doc. 2010;13:144.

7. Liu JF, Cao PL, Ge YZ, et al. Curative effect analysis of Wenxin keli in treatment of cardiac arrhythmia. Acta Acad Med Jiangxi. 2009;09: $52-54$.

8. Wang YM. Clinical study of Wenxin keli in treatment of cardiac arrhythmia. Chin Prac Med. 2007;23:3-5.

9. Cui YX. Clinical analysis of buchang Wenxin keli in treatment of arrhythmia. Chin Prac Med. 2010;26:165-166.

10. Li YB, Sun CY, et al. Clinical observation of 48 cases on Wenxin keli in treatment of arrhythmia. Chin Comm Doc. 2006;22(09):43.

11. Xie HQ. Clinical analysis of 34 cases on Wenxin keli in treatment of arrhythmia. J Kunming Med Coll. 2009;(3B):386-387.

12. Zou GX, Zhao BC. 102 cases of Wenxin keli in treatment of arrhythmia. $J$ Tradit Chin Med. 2002;09:689-690.
13. Wang CY. 150 cases of Wenxin keli in treatment of arrhythmia. Clin J Rational Drug Use. 2012;28:65-66.

14. Lou MP. 53 cases of Wenxin keli in treatment of arrhythmia. Modern Medicine. 2008;17:2627-2628.

15. Shi H. The efficacy of Wenxin keli in treatment of arrhythmia. Chemists (Academic Edition). 2012;10(12):174-175.

16. Wang MS. Clinical observation on treatment of 58 cases with cardiac arrhythmia by buchang wenxin granule. Henan Coll of Sci and Tech (Med Science). 2009;02:119-120.

17. Jin HX, Huang T. 20 cases of clinical observation on Wenxin keli treating arrhythmia. Chin Comm Doc. 2007;(15):94.

18. Xue JZ. 126 cases of clinical observation on Wenxin keli treating arrhythmia. Chin J Integr Med Cardio. 2008;3 (Suppl):103-104.

19. Ren YH, Qiao HF. 46 cases of clinical observation on Wenxin keli treating arrhythmia. Chin J Integr Med Cardio. 2005;3(3):256-257.

20. Wu XW, Yue L. 48 cases of clinical observation on Wenxin keli treating arrhythmia. Chin J Integr Med Cardio. 2004;2(8):487-488.

21. Li ZY, Shen JX. 40 cases of clinical observation on Wenxin keli treating arrhythmia. Zhejiang J Tradit Chin Med. 2011;09:698.

22. Wang DQ. 40 cases of clinical observation on buchang Wenxin keli treating arrhythmia. J Tradit Chin Med. 2010;51(7):624.

23. Pang YL. 56 cases of clinical observation on buchang Wenxin keli treating arrhythmia. Yunnan J Tradit Chin Med Mater Medica. 2010; 31(12):33.

24. Xu ZM, He YP, et al. 68 cases of clinical observation on buchang Wenxin keli treating arrhythmia. J Chin Physician. 2006;Suppl:562-563.

25. Xia DM. Clinical efficacy obseravation on buchang Wenxin particles treating arrhythmias. Modern Diagn Treat. 2010;21(6):344-345.

26. Sun XJ. 68 cases of clinical observation on buchang Wenxin keli treating ventricular contraction. Liaoning J Tradit Chin Med. 2009;09: $1530-1531$.

27. Wu Y. Clinical observation on Wenxin keli improving premature patient's symptoms and ECG. Chin J Exp Med Formul. 2009;8(15):92-93.

28. Wang HQ. Clinical observation on the safety and efficacy of Wenxin keli treating ventricular contraction. Clin Focus. 2009;12:1082-1083.

29. Guo YH. 112 cases of clinical observation on buchang Wenxin keli treating premature ventricular contractions. Med Inf. 2013;1(26):163.

30. Jin RS. Clinical observation on buchang Wenxin keli treating ventricular contractions. Chin Prac Med. 2011;17(6):164-165.

31. Zhang B, Liu F, Duan XX. Clinical observation on buchang Wenxin keli treating premature ventricular contractions. Chin J Mod Drug Appl. 2010;01:103-104.

32. Li ZM. 64 cases of clinical observation on buchang Wenxin keli treating premature ventricular contractions. Chin Hth Nutrition. 2012;12:243-244.

33. Wang YJ. 60 cases of clinical observation on buchang Wenxin keli treating premature ventricular contractions. Chin Prac Med. 2011;16: 158-159.

34. Yan GF. Clinical observation on treatment of 60 cases of premature ventricular vontraction with Wenxin granules. Guid J Tradit Chin Med Pharm. 2007;13(4):24-25.

35. Yu YH, Li BH, et al. Clinical observation on buchang Wenxin keli treating angina. Xinjiang J Tradit Chin Med Pharm. 2004;04:14-15.

36. Shu B, Li Y. Wenxin granules for treating 37 cases of angina pectoris of coronary atherosclerosis heart disease. Chin Pharm. 2013;22(16):102-103.

37. Ye GF, Shi YF, et al. Clinical study of Wenxin granule on coronary heart disease with angina pectoris. Jilin Med J. 2008;29(5):362-363.

38. Wei YQ, Zhang XW, et al. Clinical study of Wenxin keli treating unstable angina. Pract J Cardiac Cereb Pneum Vasc Dis. 2010;03:370-371.

39. Yuan KY. Clinical analysis of Wenxin keli treating unstable angina. Chin Prac Med. 2011;22:141-142.

40. Wei YQ, Deng GY. Clinical study of Wenxin keli treating angina. Liaoning J Tradit Chin Med. 2010;08:1516.

41. Yuan JQ, Wei YY. Clinical study of Wenxin keli treating unstable angina. Clin Med. 2005;03:43-44.

42. Yu T, Li DH, et al. 37 cases of clinical observation on Wenxin keli treating chronic heart failure. Jilin J Tradit Chin Med. 2006;11:9-10. 
43. Yang F, Dong ZH. Effect of Wenxin keli on chronic heart failure, plasma brain natriuretic peptide and cardiac function in patients. Zhejiang J Tradit Chin Med. 2009;01:72.

44. Kong YH, Deng CJ, Cheng W, et al. Effect of Wenxin keli on cardiac function and plasma brain natrium peptide in patients with chronic heart failure. J Clin Cardiol. 2009;25(6):428-430.

45. Xu KH. Clinical observation on Wenxin keli treating chronic heart failure. Health for Everybody (Medical Guide). 2008;04:128.

46. Hu JH. Effect of Wenxin granuleon chronic heart failure. Chin Tradit Patent Med. 2010;32(12):2035-2037.

47. Yu XF. 37 cases of clinical observation on Wenxin keli treating heart failure. Chin Prac Med. 2008;05:95-96.

48. Wang H. Clinical observation on Wenxin keli treating chronic congestive heart failure. Liaoning J Tradit Chin Med. 2012;11:2229-2230.

49. Yang LL. Clinical observation of Wenxin granule in the treatment of children with viral myocarditis. Modern Diagn Treat. 2014;20: 4634-4635.

50. Deng XC. Clinical analysis of Wenxin keli in treatment of children with viral myocarditis by assisting. Yunnan J Tradit Chin Med Mater Medica. 2012;07:86.
51. Liu PX, Ren FX. 118 cases of clinical observation on Wenxin keli treating palpitations in patients with climacteric syndrome. China Med. 2008;8(3):493-494.

52. Lei DF. 42 cases of clinical observation on Wenxin keli treating palpitations in patients with climacteric syndrome. Shaanxi J Tradit Chin Med. 2009;07:791-792.

53. Li L, Miao F. Clinical observation on Wenxin keli treating climacteric syndrome. J Changzhi Med Coll. 2010;05:343-344.

54. $\mathrm{Hu}$ XP. 35 cases of clinical observation on Wenxin keli treating climacteric syndrome. Clin Res. 2013;2:161.

55. Qi P. 32 cases of clinical observation on Wenxin keli treating arrhythmia. Yunnan J Tradit Chin Med Mater Medica. 2010;08:49.

56. Liu CL, Dong ZS. 32 cases of clinical observation on Wenxin keli treating tachyarrhythmias. Chin J Integr Med Cardio. 2005;3(1):68-69.

57. Ye F. 63 cases of clinical observation on Wenxin keli treating arrhythmia. The Chin and Forgn Hth Abs. 2013;10(10):204.

\section{Publish your work in this journal}

Drug Design, Development and Therapy is an international, peerreviewed open-access journal that spans the spectrum of drug design and development through to clinical applications. Clinical outcomes, patient safety, and programs for the development and effective, safe, and sustained use of medicines are the features of the journal, which has also been accepted for indexing on PubMed Central. The manuscript management system is completely online and includes a very quick and fair peer-review system, which is all easy to use. Visit http://www.dovepress.com/testimonials.php to read real quotes from published authors.

Submit your manuscript here: http://www.dovepress.com/drug-design-development-and-therapy-journal 